\title{
OBSERVATIONS ON THE POTENTIAL VARIATIONS OF THE CAVITIES OF THE RIGHT SIDE OF THE HUMAN HEART
}

\author{
Morley J. Kert, M.D., ${ }^{*}$ Los Angeles, Calif,, And Sibley W. \\ HoOrt.er, M.D., ANn Arror, Mich.
}

$I^{\mathrm{N}}$ 1934 Wilson, Johnston, and Hill ${ }^{1}$ published observations on the potential variations of the ventricular cavities of the dog's heart and emphasized the bearing of their observations upon the interpretation of the QRS deflections of unipolar epicardial leads. The methods described and the principles laid down in their article were used later in the analysis of the precordial electrocardiogram ${ }^{2}$ and have placed electrocardiographic interpretation upon a sounder and more logical basis. With the introduction of catheterization ${ }^{3}$ of the human heart it became possible to duplicate many of the observations made in the animal experiments referred to, and also to record the potential variations of the right auricular and right ventricular cavities in various types of cardiac abnormality which do not occur spontaneously in animals and cannot be simulated in experiments.

The first report dealing with intracavitary potential variations in man was made by Hecht ${ }^{4}$ in 1946. He concluded that the principles based on animal experiments could be applied safely to the interpretation of the human electrocardiogram. In the following year Battro and Bidoggia ${ }^{5}$ studied twelve normal subjects and eleven patients with cardiac abnormalities. They pointed out the resemblance of the tracings obtained from the cavity of the right auricle to those recorded from the auricular levels of the esophagus. In their normal subjects, leads from the right ventricle displayed a small initial $R$ wave, followed by a large $\mathrm{S}$ and a negative $\mathrm{T}$ deflection. In a case of right bundle branch block the cavity of the right ventricle was initially positive, whereas in one of left bundle branch block it was negative throughout the QRS interval. Shortly after this report appeared, Sodi-Pallares and associates ${ }^{6}$ published similar observations on six normal subjects, on twenty patients with heart disease, and on dogs studied under various experimental conditions. They found a great similarity between the records obtained in human bundle branch block and those obtained in dogs in which right or left bundle branch block had been produced experimentally. In their normal subjects, leads from the right ventricular cavity yielded curves similar to those described by other workers. With respect to the ventricular

From the Department of Internal Medicine, University of Michigan Medical School, Ann Arbor, Michigan.

Much of the work upon which this article is based was done with the aid of grants to Dr. Frank N. Wilson from the Horace H. Rackham School of Graduate Studies and the S. S. Kresge Foundation. and in part by a grant from the United States Public Health Service.

*Aided by a Fellowship from the Dazian Foundation for Medical Research. 
complexes of these leads, patients with right ventricular hypertrophy dicl not differ significantly from normal subjects; those with left ventricular hypertrophy differed only in that the direction of the $T$ wave was upward.

The purpose of our own studies has been to confirm and extend the observations published by others, and in particular to compare the potential variations of the cavity of the right ventricle with those of the right side of the precordium in various types of heart disease.

\section{METHODS AND MATERIAL}

We are reporting here only those cases in which it was possible to obtain leads from the cavity of the right auricle and a lead from at least one point in the cavity of the right ventricle.

The fifteen patients studied have been divided into four groups. Group $A$ contains six patients with pulmonary stenosis with or without the other features of the tetralogy of Fallot. These patients were cyanotic and all presented evidence of pronounced right ventricular enlargement. Group $B$ consists of three patients with essential hypertension and varying degrees of left ventricular enlargement. Group $C$ is made up of two hypertensive patients with right bundle branch block. The remaining patients, constituting Group $D$, did not display abnormal preponderance of either ventricle. One had a patent ductus arteriosus; one had had a pericardiectomy for constrictive pericarditis; and two were normal.

All intracavitary electrocardiograms were recorded simultaneously with lead $\mathrm{V}$, by means of a Sanborn Tri-beam Electrocardiograph. Most of the intra-auricular tracings were taken with this instrument operating at the standard sensitivity; in the majority of the intraventricular tracings a deflection of $1.0 \mathrm{~cm}$. represents a potential difference of 3.0 millivolts.

In most instances the electrocardiographic observations were supplemented by measurements of the intracavitary pressures and of the oxygen content of the blood in the chambers on the right side of the heart. In the early cases the catheters used were of the type in which a small wire, terminating in an electrode, is embedded in the catheter wall. Catheters of this kind were found to have two disadvantages: the wire incorporated in the wall reduces the size of the lumen, which makes the withdrawal of blood samples difficult, and by decreasing the flexibility of the catheter, makes its introduction into the right ventricle and the pulmonary artery more difficult.

We, therefore, adopted the following technique. An ordinary $8 \mathrm{~F}$ or $9 \mathrm{~F}$ Cournand-type single lumen catheter was first advanced as far as desired. A wire stylet* of spring steel was then advanced through the catheter until its end was within two to three inches of the orifice. The wire was led out of the proximal end of the catheter through a hole bored near the outlet of a standard three-way stopcock, and connected to the electrocardiograph. Inasmuch as the stylet

*The stylets used were supplied by the United States Catheter and Instrument Co. for use with the Cournand catheter. They were of stainless steel, $0.016 \mathrm{inch}$ in diameter, and the end was previously heated to form a small bead and thus prevent injury to the inner surface of the catheter during the insertion of the wire. Before each use the stylet was examined and tested carefully for possible flaws, to guard against the possibility of breakage during the process of insertion. 
entered beyond the valve in the stopcock, it was possible to record pressures, to draw samples, or to maintain the infusion without altering the position of the recording wire within the catheter. When electrocardiographic tracings were taken, valuable information as to the location of the catheter tip could be obtained by recording the pressure at its orifice or by obtaining a sample of blood. The presence of the wire within the lumen of the catheter did not appear to alter significantly the pressure tracings taken with a Hamilton manometer, nor did it induce thrombus formation during the withdrawal of blood samples. As a precaution against the latter complication, a high, local concentration of heparin within the catheter was insured, not only by the addition of ten units of heparin per liter to the infusion fluid, but also by the preliminary injection of a stronger concentration of heparin solution just prior to the blood sampling.

Although the distal end of the stylet was never at the end of the catheter, and in a few instances could not be advanced to a point less than four or five inches from it, the potential variations recorded were clearly those taking place at the catheter orifice, for the catheter was a nonconductor. The effect of increasing the distance from the distal end of the stylet to the tip of the catheter was examined and it was found that as this distance became larger the resistance in the electrocardiographic circuit rapidly increased. As this resistance rose, the tracing recorded showed increasing distortion due to stray sixty-cycle current. The general outline of the electrocardiographic deflections was not altered in other respects, even in instances in which the distance from the distal end of the stylet to the catheter tip was increased to as much as three feet. At this distance, however, the voltage of these deflections was only about one-half as great as when the end of the stylet was only a few inches from the orifice of the catheter (Fig. 1).

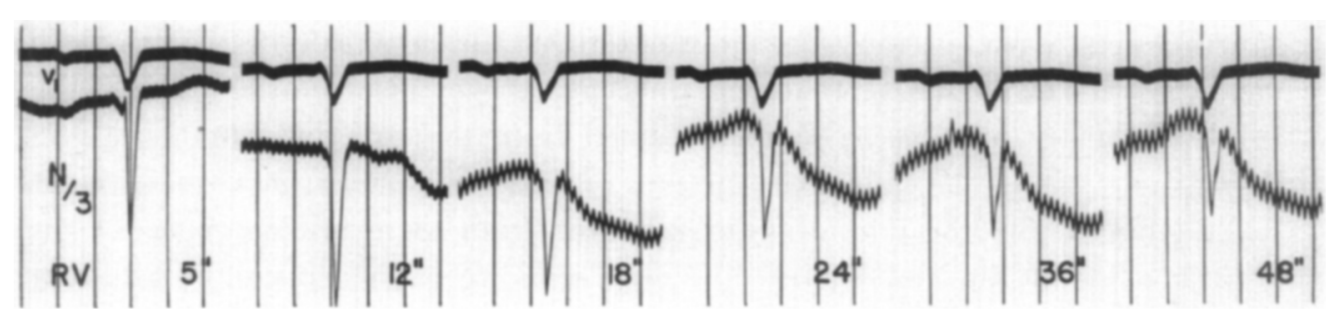

Fig. 1.--Normal subject. U pper beam, Lead $v_{k}$. Lower beam, lead from the right ventricle taken with the electrocardiograph at normal sensitivity. The number at the right lower corner of each strip gives the distance in inches of the elcetrode tip from the intraventricular opening of the catheter.

The suitability, for our purpose, of wires made of various metals was examined by testing them in saline solutions. Although these tests showed that some metals gave larger polarization effects than others, there was no significanl difference between the electrocardiograms obtained wilh different lypes of electrodes.*

*The authors are indebted to Professor Alfred L. Ferguson, Department of Chemistry, University of Michigan, for his valuable assistance in these problems. 
Although the position of the catheter orifice could usually be ascertained by fluoroscopy, pressure readings were relied upon to determine without question that the catheter tip had entered or had been withdrawn from the right ventricle or pulmonary artery. An attempt was made to obtain records from at least three positions within the right ventricle. Position $I$ is defined as that in which the catheter tip has just entered the right ventricle from the auricle and lies on the ventricular side of the tricuspid valve. The catheter orifice can be brought into this position by being advanced slowly until the smaller pressure variations characteristic of the right auricular cavity are replaced by the larger pressure variations characteristic of that of the right ventricle. Position III is that occupied by the catheter tip when it has been withdrawn from the pulmonary artery and lies on the ventricular side of the pulmonary valve. This position can be identified by the taking of a continuous pressure tracing as the catheter tip is being withdrawn after fluoroscopy has demonstrated its entrance into the pulmonary artery or one of its branches. The arrival of the catheter tip at the desired point is recognized by the sudden transition from the pulse pressures characteristic of the pulmonary artery to the larger pressure variations dependent upon the low diastolic pressures in the right ventricle. Position II is that occupied by the catheter tip when fluoroscopy shows that it lies near the cardiac apex and the pressure readings are those characteristic of the right ventricle. It was not always possible to obtain recordings from each of the three positions specified; for, in some instances, the catheter could not, for one reason or another, be advanced to the cardiac apex, or could not be introduced into the pulmonary artery.

In each case leads were taken from three positions in the right auricle. These were determined fluoroscopically and were called high, mid, and low. In the first of these, the catheter tip had just entered the right auricle from the superior vena cava; in the third, it was on the auricular side of the tricuspid valve; and in the second, it was approximately midway between the first and the third. Tracings were occasionally obtained from the superior vena cava and from points within the pulmonary artery. In addition, sometimes the catheter was advanced into the inferior vena cava and from there into branches of the hepatic vein, for the purpose of obtaining semidirect leads from the adjacent parts of the epicardial surface of the right or left ventricle (Fig. 5). Our cxperience with these last leads is limited, but it is felt that they may be of some value.

The intervals from the beginning of the QRS interval to the peak of the $R$ wave and to the nadir of the $S$ wave were measured* to the nearest thousandth of a second both in Lead $V_{1}$ and in leads from the cavity of the right ventricle. In some instances these measurements were extended to other leads or other deflections.

*All measurements were made by means of a device designed by Captain B. H. Eliot and manufactured by The Cambridge Company, Ossining, N. Y. 


\section{OBSERVATIONS}

Extrasystoles.--Premature ectopic beats occurred frequently in some patients and infrequently or not at all in others. Auricular extrasystoles appeared while the catheter was in the right auricle in only one case (Fig. 2). Ventricular extrasystoles, however, were recorded on several occasions when the catheter was in Position II or III in the right ventricle, and could be made to disappear by withdrawing the catheter a few centimeters.
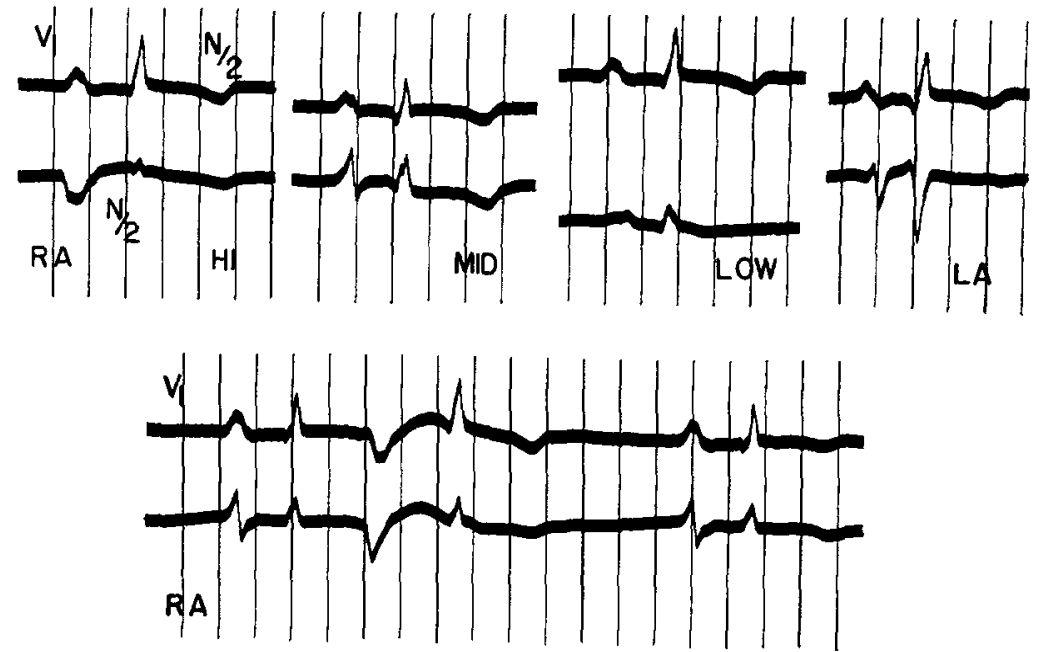

Fig. 2,- Tetralogy of Fallot. Upper beam, Lead $V_{I}$ taken with the electrocardiograph at one-half the normal $(N / 2)$ sensitivity. Lower beam, tracings from high (Hi), mid-, and low positions in the right auricle, and from the left auricle $(L A)$. The lower strip is a lead from the mid-position in the right auricle and the second complex represents an auricular extrasystole followed by a compensatory pause.

In the type of ventricular extrasystoles usually seen, Lead $V_{1}$ displayed a broad, bizarre $Q S$ complex (or a broad $S$ wave preceded by a tiny $R$ wave), and in the leads from within the right ventricle the normal initial positivity disappeared, so that the QRS complex was represented by a broad, downward deflection (Fig. 7). Such extrasystoles were attributed to a focus on the endocardial surface of the right ventricle. In one tracing, however, an ectopic ventricular beat occurring after a period of cardiac standstill induced by carotid sinus pressure is represented in Lead $V_{1}$ by a deep, broad $S$ wave, preceded by a very small $R$ wave, and in a lead from the cavity of the right ventricle (Position II), by a $Q R S$ complex consisting of a broad, notched $R$ wave followed by a small $S$ wave (Fig. 3). It is not certain that this ectopic beat was initiated by the presence of the catheter, but if it arose on the endocardial surface of the right ventricle, the electrocardiographic pattern which it produced is difficult to explain. In that case one would anticipate initial negativity of the ventricular cavity. It clearly had its origin near the cardiac base, for during the larger part of the QRS interval the excitation was spreading away from the precordial electrode near the base and toward the cavity electrode which was near the apex. There is a widespread belief that extrasystoles usually originate in the Purkinje system. ${ }^{7}$ 

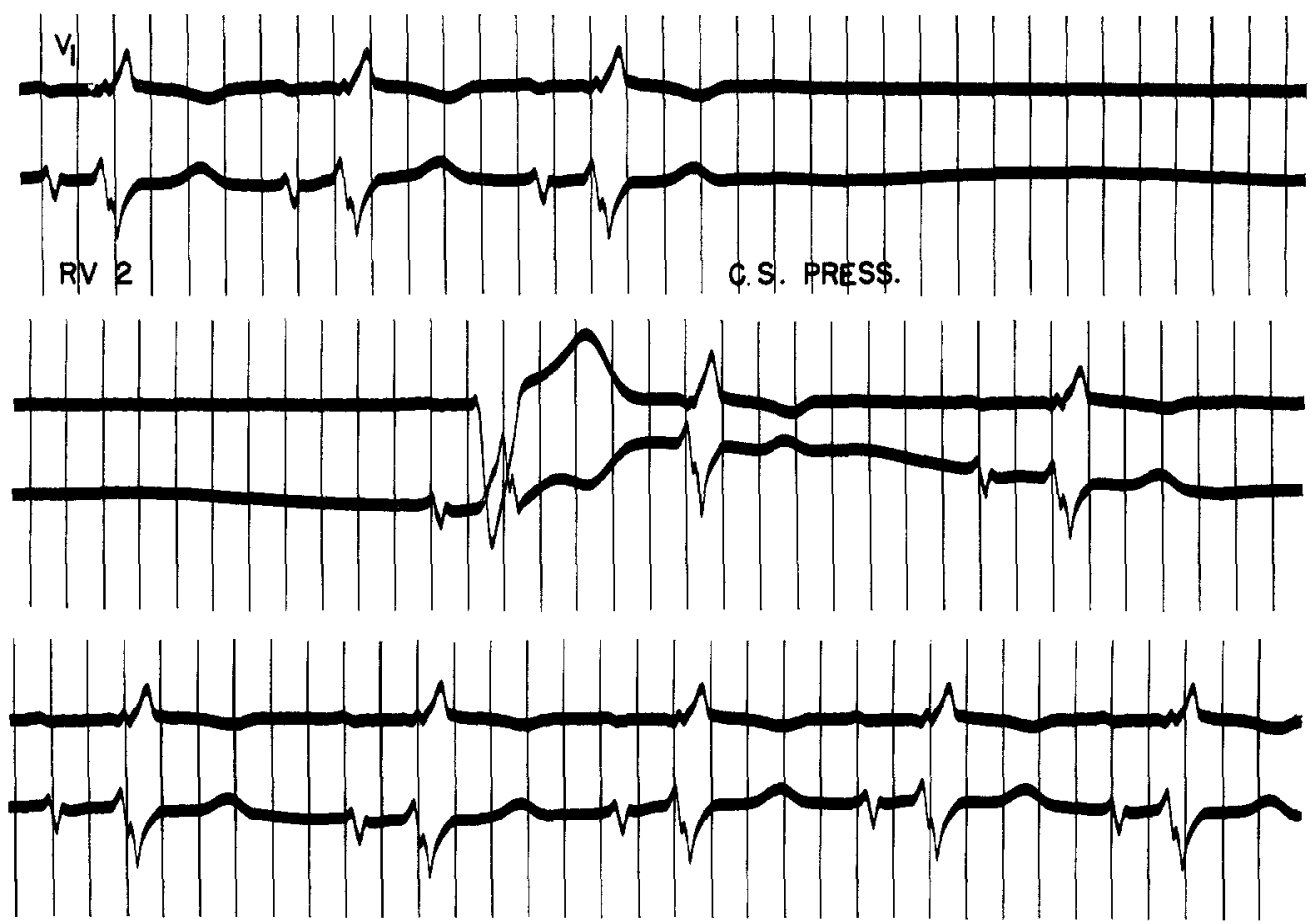

Fig. 3,-- Right bundle branch block. I'pper beam, Lead $v_{l}$. Lowor beam, lead from P'osition II in cavity of right ventricle taken at $\mathrm{N} / 3$ sensitivity. The three strips are continuous. Lpper strip shows the beginning of prolonged pause following carotid sinus pressure. First complex in the second strip represents an ectopic beat (seo text).

Endocardial Effects.-Upward displacement of the RS-T and P-R segments of variable magnitude occurred when the catheter came in contact with the endocardium of the right ventricle or right auricle (lig. 5). The muscle region affected was obviously small, for displacement of the RS-T segment was never detected in the lead from the right side of the precordium $\left(V_{1}\right)$. When the catheter was withdrawn one or two centimeters, the displacement in the cavity lead promptly disappeared and the first part of the QRS complex recorded from the new position generally resembled in form that recorded when the catheter was in contact with, or very close to the endocardium. In a few instances, however, it was noted that the peak of the initial $R$ wave in the earlier tracing was considerably later (Fig. 8) than in that recorded after the catheter tip had been pulled back. This would seem to indicate that pressure of the catheter against the endocardium may in some instances delay conduction in the right Purkinje plexus, in one of the subdivisions of the right bundle branch, or in this structure itself. In one case of hypertension complete right bundle branch block was present only during the catheterization procedure.

Artifacts.--Occasionally, small, broal, pusitive waves (Fig. 4) occurred at regular intervals without relation to the heart beat. In a few instances these occurred sporadically. No explanation for these rhythmic deflections can be offered. 


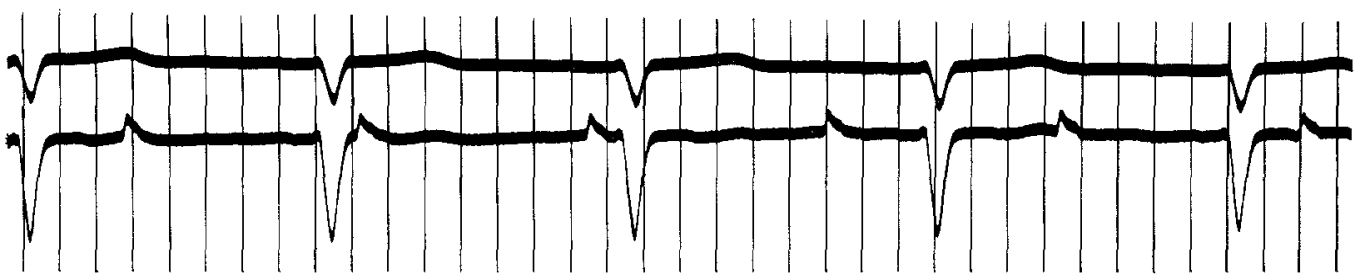

Fig. 4.-Case of hypertension. Rhythmic artifacts of unknown origin, Lpper beam, Lead $V_{1}$ normal sensitivity. Lower beam, lead from Position Il displaying broak, positive waves occurring fairly regularly but bearing no relation to the events of the cardiac cycls. P' waves can be seen indistinetly in both upper and lower tracings and the $P$ - $R$ interval is constant.

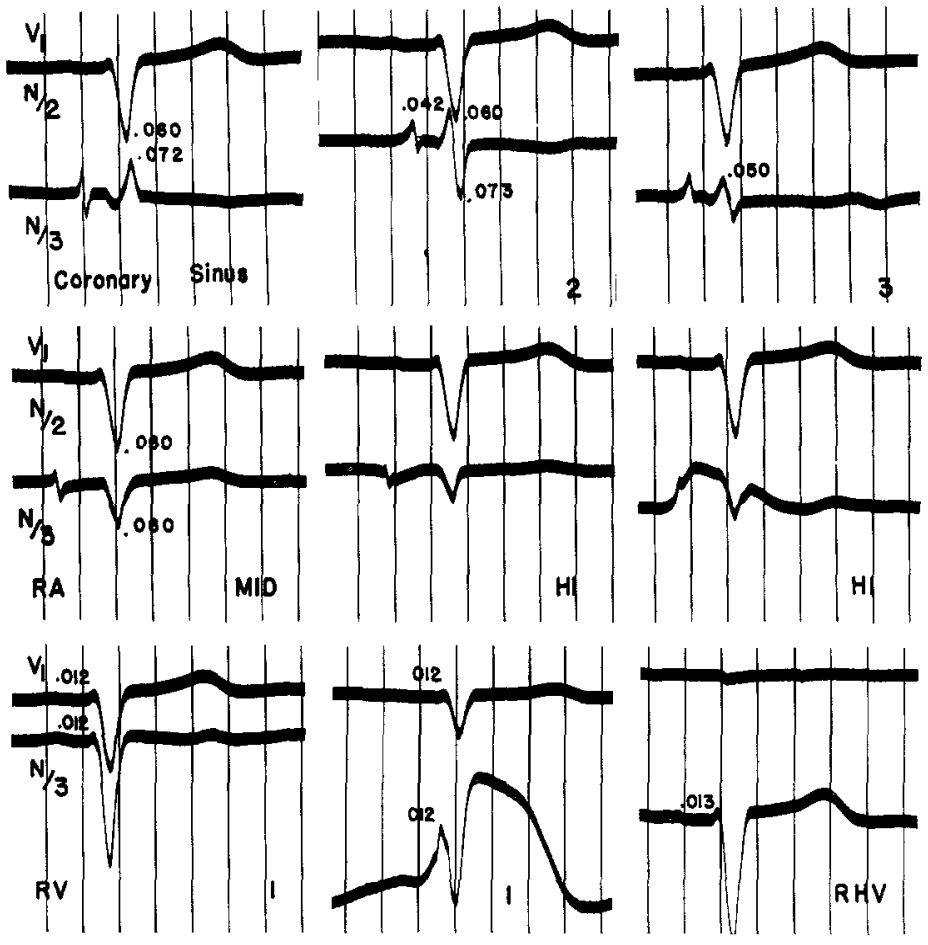

Fig. 5.-Essential hypertension. Upper boam, Lead $V_{1}$ taken at $N / 2$ sensitivity. In the second strip of the third row the sensitivity of the upper beam is less than normal and in the third strip it has diminished to almost zero. The lower beam of the upper row shows leads from three different positions in the coronary sinus and in contrast to the leads from the auricular cavity exhibits a short P-R interval and larger $\mathbf{R}$ deflections. Lower beam of the second row, leads from the right auricle. The third strip in this row is from the same region as the second, but the electrode was against the auricular wall. In the third row the lower beam represents a lead from l'osition $I$ in the right ventricle; first, with the catheter free in the cavity, and second, with the catheter in contact with the endocardium. Tho third and last strip is a lead from the right hepatic vein; the ventritular complex is like that of the intracavitary leads except that the $T$ wave is upright. 

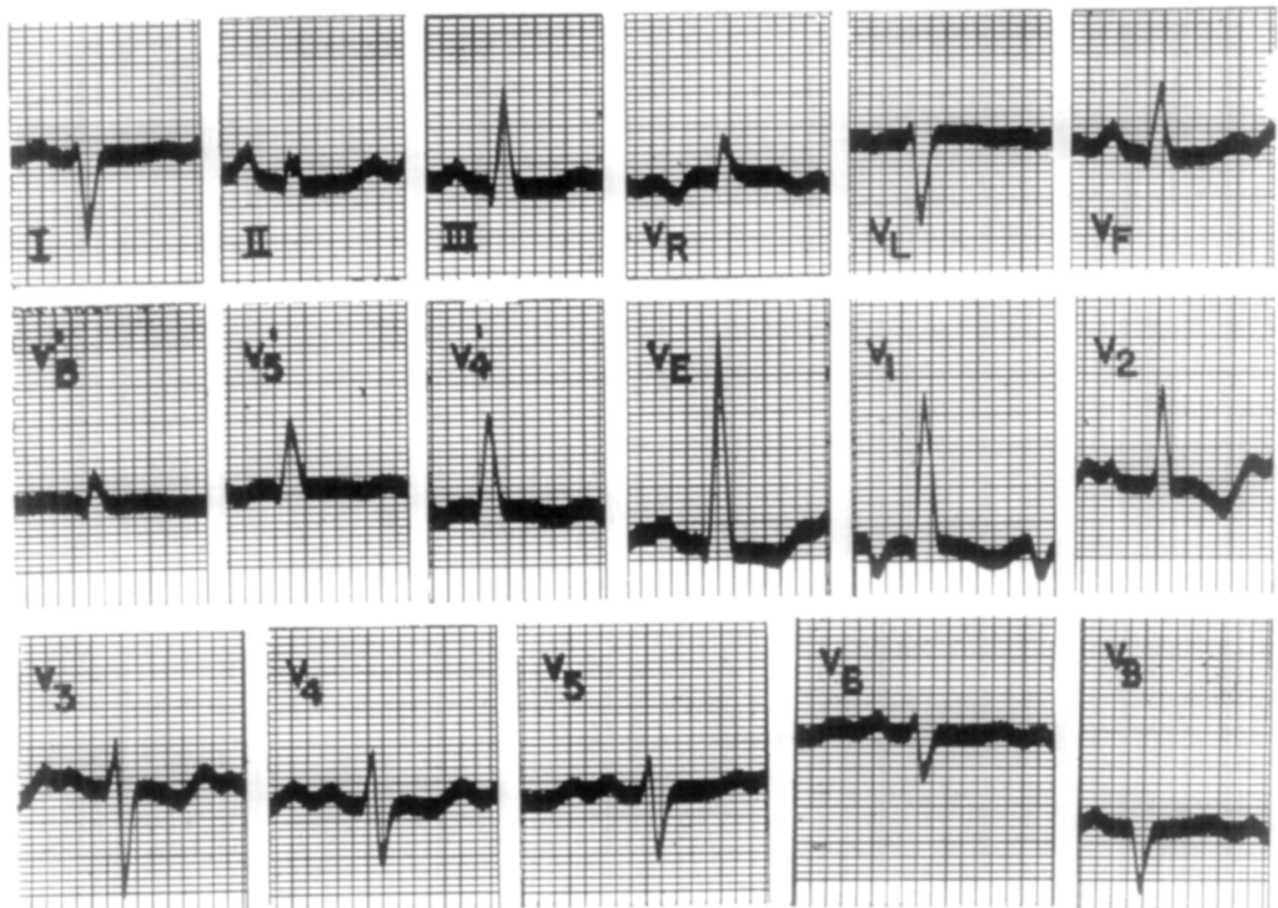

Fig. 6A. Tetralogy of Fallot. Standard and augmented unipolar limb leads. Second and third rows show six standard precordial leads; a lead from the ensiform process $\left(V_{E}\right)$; a lead from the angle of the scapula at the level of the apex $\left(V_{B}\right)$. The $V^{\prime}{ }_{3}$ is a lead from a point on the right side of the chest corresponding to the point on the left side from which $V_{3}$ is taken. The symbols $V_{4}^{\prime}, V_{5}^{\prime}$, etce, have the same significance.
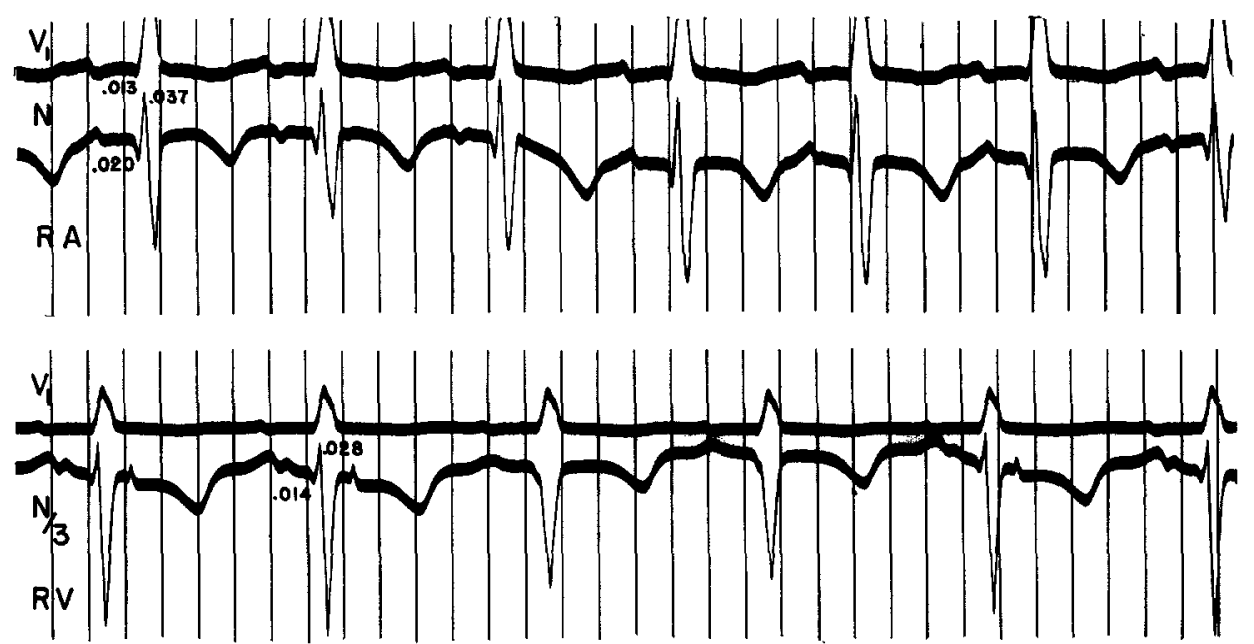

Fig. 6B.-Same patient as Fig. 6A.-Upper beam, Lead $V_{1}$. In the upper row Lead $V_{1}$ is at normal sensitivity and the lower beam shows a lead from the right auricle taken at normal sensitivity. The variations in the form of the complexes are due to respiratory changes in the position of the electrode (see text). In the lower strip $V_{1}$ is at $N / 2$ sensitivity and the lower beam shows a lead from within the right ventricle taken at $\mathrm{N} / 3$ sensitivity. Here also the variations in the form of the complexes are due to respiratory movements of the catheter tip. 
Intra-auricular Electrocardiograms.-In general, our observations are in greement with those of previous workers ${ }^{4,5,6}$ and are in accord with the predicions of the dipole theory. ${ }^{8}$ When the catheter tip is above the sinus node so that the auricular excitation wave spreads away from it, the $\mathrm{P}$ wave lies entirely below the isoelectric level. When the exploring electrode is in the middle of the auricular cavity so that the impulse first approaches, and then passes it, the $\mathrm{P}$ wave is of the RS type, with the peak of the $\mathrm{R}$ wave representing the arrival of the impulse at the level of the electrode. In leads from the lowest portion of the auricular cavity the $P$ wave is predominantly positive (Fig. 7). In one instance it was observed that the auricular complex regularly passed through the three forms, that is, from positive to diphasic to negative, while the P-R interval remained constant (Fig. $6 B$ ). It was apparent that this cycle was due to respiratory variations in the position of the catheter tip. In a few instances we were able to produce similar changes in the $\mathrm{P}$ waves by instructing the pa-
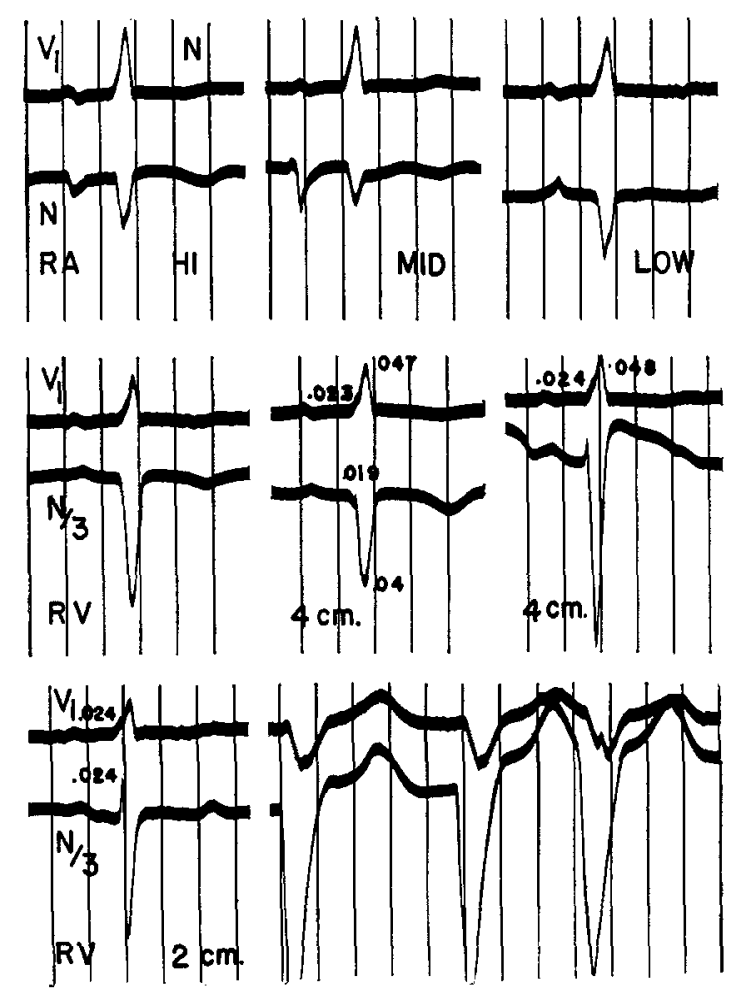

Fig. 7.-Tetralogy of Fallot. Upper beam, Lead $V_{1}$. The electrocardiograph was adjusted to normal sensitivity, but because of the condition of the batteries the sensitivity gradually fell to approximately N/2. Lower beam, upper row; leads from the right auricle. First strip of second row shows a lead from Position I in the right ventricle. The next two strips show leads from the right veutricle; fluroscopic control showed the catheter tip to be $4.0 \mathrm{~cm}$. to the left of the midsternal line. The catheter was against the endocardial wall when the second strip was taken. Lower beam, third row, shows a lead from within the right ventricle with the catheter tip $2.0 \mathrm{~cm}$. to the left of the midsternal line. The last three complexes represent extrasystoles with the cathetor at the samo position. Note the close correspondence between the $R$ wave of the cavity lead and the notch in $V_{1}$ when the catheter was not against the wall. The small numbers to the third decimal place indicate the time in seconds of the adjacent peak with reference to the beginning of the QRS interval. 
tients to breathe deeply. With the electrode in the midauricular position, the $P$ waves were of the RS type during quiet respiration. During inspiration the electrode shifted to the upper portion of the auricle, and the $\mathrm{P}$ wave was of the QS type, whereas in expiration when the electrode moved in to the lower portion of the auricular cavity, the l' wave was upright.

In one case of congenital heart disease the $P$ waves in the leads from the right side of the precordium were broad and notched. Because of the presence of a patent interauricular septal defect, it was possible in this instance to obtain electrocardiograms from the midportions of both the right and left auricles. In the lead from the right auricle the intrinsic deflection corresponded in time to the first notch of the $\mathrm{P}$ wave of Lead $V_{1}$. In the lead from the left auricle the $\mathrm{P}-\mathrm{R}$ interval was shorter and the intrinsic deflection corresponded in time to the second notch of the $\mathrm{P}$ wave in the precordial lead. The QRS complex of the lead from the right auricle differed strikingly from that of the lead from the left. The former was dominated by a large $R$ wave, whereas the chief deflection of the latter was downward (Fig. 2). The patient had extreme right ventricle enlargement and it is suggested that the lead from the right auricle reflected the late activation of the base of the hypertrophied right ventricle, and that from the left auricle, the negativity of the left ventricular cavity.

In another instance, fluoroscopy, blood sample showing an oxygen content of seven volumes per cent, and extremely low pressure readings indicated that the catheter was in the coronary sinus. The tracing from this region, that is, the groove between the left auricle and the left ventricle, displayed a shorter P-R interval than that from the right auricle. 'This observation may be regarded as additional evidence that the left auricle is activated later than the right. The patient had left ventricular enlargement. In contrast to the observations on the patient with right ventricular enlargement, previously described, the QRS complex of the lead from the right auricle consisted of a QS wave. In the leads from different positions in the coronary sinus, however, the QRS complex displayed a prominent $R$ wave (Fig. 5). These positive waves differed in time from one position to another and it is suggested that they reflect the activation of different portions of the base of the left ventricle.

Previous workers ${ }^{4.3}$ have noted that the complexes of leads from the upper levels of the right auricle are often similar in form to those of I.ead $V_{R}$. The majority of our cases showed a resemblance of this kind. There were a few instances, however, in which the form of the QRS complex in Lead $V_{R}$ was like that of the leads from the lower portion of the right auricle. Sometimes the QRS complex of the leads from the auricle displayed a prominent $Q$ wave which preceded in time the initial positive ventricular deflection of the leads from the right ventricle. We have no adequate explanation for this early auricular negativity, but it is necessary to consider that an electrode in the right auricle may reflect the potential variations produced by the left, as well as those produced by the right ventricle.

Intraventricular Electrocardiograms.--Other investigators ${ }^{4,5,6}$ have observed that as a rule the cavity of the right ventricle is positive at the beginning of the 
QRS interval. This initial positivity has been atrifuted to early activation of the upper portion of the septum from left to right; in other words, to what may be considered physiologic incomplete right bundle branch block. An initial $R$ wave was present in the leads from the cavity of the right ventricle in all of our cases. The amplitude of this early $R$ wave varied, however, with the position of the catheter within the right ventricle. The $R$ wave of the lead from Position I was frequently smaller than that of the leads from Positions II and II I and, in a few instances it was absent so that the QRS complex was represented by a QS deflection (Fig. 7). This deflection often displayed a notch or slur on the descending limb, corresponding in time to the $R$ wave recorded in the lead from Position II or III in the same case. When these notches or slurs occurred, they were not constantly present, but came and went rhythmically. In one instance, with the catheter tip at Position I there were periodic transitions from an uncomplicated QS wave, to one notched on its descending limb, and from this form to a complex of the RS type. In this case (Fig. 6B) there was an intraventricular septal defect, and we considered the possibility that the catheter tip was entering and leaving the left ventricle. It may well be, however, that the variations in question were due to changes in the position of the exploring electrode in relation to the septum. As in the case of the similar vatrations in the aluricular complex seen in auricular leads, we examined the effect of respiration unon the form of the complexes of intraventricular leads in several instances. I1 was found that during deep inspiration, which would be expected to shift the tip of the catheter toward the base of the heart, the initial $R$ wave sometimes became smaller, whercas expiration made it larger (Fig. 9B). This finding is in accord with the observation that the $R$ wave is ordinarily smaller in the lead from Position I than in that from Position II or III. It seems to us necessary to reexamine the concept that the uppermost part of the left side of the septum is activated earlier than any other.

The $P$ waves of the intraventricular tracings were generally small and upright and the $\mathrm{T}$ waves were usually inverted. Exceptions to the latter rule will be discussed in a later section.

Relations Between Precordial Leud $\mathrm{T}^{\top}$ and Leads From the Right I'entricle.-Since $V_{1}$ is the precordial lead which is thought to reflect best the potential variations of the surface of the right ventricle, it was considered desirable to compare this lead with the leads from different points within the right ventricle. We hoped in this way to obtain a better understanding of the form of the ventricular complex in leads from the right side of the precordium, particularly in cases of right ventricular enlargement and right bundle branch block. Before presenting the findings in each of our four groups of patients, it seems appropriate to consider briefly a few of the concepts involved in a discussion of this type.

Let us consider, to begin with, the forces produced by activation of the septum in a direction perpendicular or nearly perpendicular to its endocardial faces. The potentials of the two ventricular cavities may be expected to differ in sign only when there are one or more boundaries between active and resting muscle in the septum. When one side of the septum is activated before the other, the 
homolateral cavity is initially negative and the contralateral, initially positive. The normal, initial positivity of the right ventricular cavity in man is, therefore, attributed to early activation of the septum from left to right.

We may conclude, then, that activation of the septum in the normal fashion has opposite effects upon the potentials of the two cavities. It has the same effect upon each cavity and the epicardial surface of the free ventricular wall which bounds it. In contrast, the activation in the normal fashion of one of the free ventricular walls has opposite effects upon the potentials of its inner and outer surfaces, but affects the potentials of both ventricular cavities in the same way. These statements, of course, concern the sign of the potentials referred to, not their magnitude. When a boundary hetween artive and resting muscle is established between the cavity and the epicardial surface of the right ventricle by an impulse spreading through its free anterior wall from within outward, the presence of this boundary will tend to make the epicardial surface of the wall positive and the ventricular cavity negative. The potential of the precordium is under all ordinary circumstances of the same sign with reference to an indifferent point, such as the central terminal, as that of the nearest part of the epicardial surface. But the magnitude of the potential of the precordium in comparison with that of the nearest part of the cpicardium is dependent upon a variety of factors and is not easily predictable.

With reference to the comparison of the ventricular complexes of a lead from the right side of the precordium and the ventricular complexes of a lead from the cavity of the right ventricle, the following conclusions seem to be justifiable when, but only when, the ventricles are responding to impulses which reach them solely by way of the bundle of His, regardless of whether all subdivisions of this bundle are conducting normally. When a deflection in one direction occurs in the precordial lead simultaneously with a deflection in the opposite direction in the cavity lead, both deflections should be attributed to forces across a boundary between active and resting muscle in the free wall of the right ventricle. On the other hand, when a deflection in one direction in the precordial lead occurs simultaneously with a deflection in the same direction in the cavity lead, it is justifiable to conclude that the cavity deflection is shaped by forces arising at a boundary between active and resting muscle lying in the ventricular septum or the free wall of the left ventricle. The precordial deflection must be attributed in part to the same forces, but the possibility that it also represents forces generated in the free wall of the right ventricle cannot be excluded.

The initial activation of the septum from left to right which normally occurs prior to the activation of the free wall of the ventricles is represented by an $R$ wave in the leads from the precordium which reflect the potential variations of the right side of the septum (Lead $V_{1}$, and possibly Leads $V_{2}$ and $V_{E}$ ) and by a $Q$ wave in those leads which reflect the potential variations of the left side of the septum (Leads $V_{5}$ and $V_{6}$ in about 50 per cent of normal subjects and leads from the left back).

In normal subjects and in patients with left ventricular enlargement, the small initial $\mathrm{R}$ deflection which occurs in the leads from the right side of the 
precordium is more or less simultancous with the initial $R$ wave of the leads from the cavity of the right ventricle. It is justifiable, therefore, to conclude that the precordial $R$ wave is due in part to forces of septal origin. After the inscription of this initial $\mathrm{R}$ wave the precordium and the cavity of the right ventricle are negative, and it is clear that this negativity is due to activation of the septum from right to left, to activation of the free walls of the two ventricles from within outward, or to both. The rapid increase in the negativity of the right ventricular cavity early in the QRS interval, for which these septal and left ventricular forces are responsible, causes the part of the precordial $R$ wave due to activation of the thin free wall of the right ventricle to be much less conspicuous than it would be if it were written on a horizontal base line instead of a steep downward slope. The size of this $R$ wave is not proportional to the voltage across the right ventricular wall. In right ventricular hypertrophy, on the other hand, the activation of the thick free wall of the right ventricle produces voltages that are greater or develop more rapidly than the septal and left ventricular forces in question and are also of longer duration. Under these circumstances the potential of the epicardium of the right ventricle and the right precordium are positive for a considerable period during which the potential of the ventricular cavity is negative. In right bundle branch block the activation of the free wall of the right ventricle occurs so late in the QRS interval that the forces which it produces are unopposed. Here again the potential of the cavity and the potential of the epicardial surface of the right ventricle are opposite in sign.

The principles applicable to interpretation of the deflections produced by depolarization are equally valid in the interpretation of those which accompany repolarization. The $\mathrm{T}$ wave in leads from the epicardial side of the free wall of the right ventricle will differ in direction from that inscribed in leads from the ventricular cavity side only when the forces produced by repolarization of the free wall of the right ventricle are not overbalanced by those produced by repolarization of other parts of the heart. In the majority of normal adults the $T$ waves are upright in the leads from the right side of the precordium and inverted in leads from the right ventricular cavity. This implies that repolarization takes place earlier on the epicardial than on the endocardial side of the right ventricular wall; in other words, the repolarization process spreads from the epicardial toward the endocardial surface. When the $T$ waves have the same direction in leads from both sides of the free wall of the right ventricle, their form is evidently determined to a large extent by forces produced by repolarization of the septum or the free wall of the left ventricle. Under these circumstances the present method of investigation does not furnish reliable information concerning the direction of repolarization in the free wall of the right ventricle. Such information could be obtained only by measuring the voltage across the wall during the inscription of the $T$ wave by leading from its endocardial to its epicardial surface.

Group. 1. Cases of Right Ventricular Enlargement.-The majority of our cases of this kind were examples of extreme right ventricular enlargement. The precordial electrocardiogram, therefore, was of the type displaying tall $R$ 
waves in the leads from the right side of the precordium and small $\mathrm{R}$ and deep $\mathrm{S}$ waves in the leads from the left side (Fig. $6 A$ ). In one case in which the clinical diagnosis was tetralogy of Fallot the large $\mathrm{R}$ deflection of the leads from the right side of the precordium was preceded by a $Q$ wave (Fig. $6 A$ ). The leads from within the right ventricle also displayed a $Q$ deflection and this was simultaneous with the $Q$ wave in lead $V_{1}$ (Fig. $6 B$ ). It can hardly be doubter that the precordial $Q$ wave and the cavity $Q$ wave are alike in origin, but there is no entirely satisfactory explanation for the occurrence of a $Q$ deflection in leads from the right ventricular cavity. Several possibilities may be considered. There was no $Q$ wave in the leads from the left side of the precordium and the left side of the back, but this deflection occurred in all the leads from the right side of the precordium and in a lead from the posterior aspect of the right chest (Fig. 6,A). If the $R$ wave of the cavity lead in this case is attributed to activation of the left sicle of the septum before the excitation process reached the right side by way of the right branch of the bundle of His, the still earlier $Q$ deflection must be ascribed to an excitatory process traveling away from the exploring electrode through left ventricular muscle. If the cavity $Q$ wave were due to forces arising in the free wall of the right ventricle, it would be expected to be simultaneous with an upward deflection in Lead $V_{1}$. If we ascribe this deflection to activation of the septum from right to left, we must assume that the right side of the septum was activated before the left; or, that the two sides of the septum were activated simulaneously and the forces produced by activation of the right side of this structure overbalanced those produced by activation of its left side during the earliest phases of the QRS interval. It seems unlikely that there is a minor defect in left bundle branch conduction in those cases of right ventricular hypertrophy in which the right ventricular cavity is initially negative, for this hypothesis does not satisfactorily account for the rather prominent $R$ wave which follows the small $Q$ wave in right cavity leads. It is conceivable that in these cases excitation begins or develops most rapidly in the free wall of the left ventricle or in one of the papillary muscles in the left or right side of the septum. Whether the presence of a defect in the ventricular septum is in any way responsible for the phenomenon in question is also a matter for conjecture. It is hardly worth while to speculate further until more data are available, but it should be noted that occasionally in dogs there is initial negativity of the right ventricular cavity, even in the presence of right bundle branch block. ${ }^{2}$, Fig. 6

Four of our patients with right ventricular enlargement displayed notching or slurring of the upstroke of the tall $\mathrm{R}$ wave of Lead $V_{1}$. In three of these the $R$-wave peak in the cavity lead corresponded closely in time to the notch or slur in Lead $V_{1}$ and the peak of the $R$ wave in the precordial lead was related closely in time to the $\mathrm{S}$ deflection of the leads from the cavity of the right ventricle (Fig. 7). It seems evident, therefore, that in cases of this type the $\mathrm{R}$ wave in Lead $V_{1}$ represents forces produced by activation of the septum from left to right followed closely by the activation of the free wall of the right ventricle from within outward. The form of the precordial QRS complex in these cases is reminiscent of that seen in cases of complete right bundle branch block. In these the QRS interval is longer ( 0.12 second or more), but the $R$ wave of 
Lead $V_{1}$ is often conspicuously slurred and notched. Leads from points farther to the right, however, usually display double $\mathrm{R}$ waves. In the cases with which we are clealing, the QRS interval measured less than 0.10 second, but beause of the form of the QRS complex in Lead $V_{1}$, incomplete right bundle branch block was frequently suspected. The initial $R$ deflection in the leads from the right ventricular cavity in our four cases, however, does not differ appreciably from that recorded in normal subjects. Furthermore, leads from points to the right of the right sternal margin did not display double $R$ waves. Thus, it seems unlikely that more than the physiologic degree of incomplete right bundle branch block was present in these cases.

In five of the six cases of Group 1, Iead $V_{R}$ rlisplayed a late $R$ wave and the QRS complex of this lead resembled that of one or more of the leads from the cavity of the right auricle.

In three cases the $T$ waves were upright in the leads from the right side of the precordium and inverted in those from the right ventricular cavity. 'This pattern is the rule in normal subjects and, as already noted, suggests that repolarization takes place earlier on the epicardial side than on the endocardial side of the right ventricular wall. In the other three cases the $T$ waves were inverted both in the leads from the right side of the precordium and in those from the right ventricle, and this $T$-wave pattern is ascribed to the course of repolarization in parts of the heart other than the free wall of the right ventricle. It does not permit any conclusion as to whether repolarization of this wall begins on its inner or outer surface. It should be noted, however, that in all six cases of right ventricular enlargement the QRST area of the cavity leads was clearly negative, whereas that of Lead $V_{1}$ was clearly positive. This indicates that the gradient in the length of systole, or speaking more strictly, in the time course of excitation and recovery, across the free wall of the right ventricle was of the same kind in all of them.

Group 2. Right Bundle Branch Block.-The two patients in this group hal moderate hypertension. One patient displayed complete right bundle branch block only during catheterization, and it is possible that the conduction defect was initiated by this procedure. The other patient was unusual in that the right bundle branch block usually disappeared when the heart rate was reduced by carotid sinus pressure. During the catheterization carotid sinus pressure caused pronounced cardiac slowing but did not abolish the block (Fig. 3).

In both cases there was a broad, initial $R$ wave in the leads from the right ventricle. As in the other cases the size of this deflection varied with the level of the electrode, and in both instances its voltage was smaller in the lead from Position I than in the lead from Position II. In each case it was clear that the initial positivity of the cavity was responsible, at least in part, for the early. $R$ wave in I.ead $V_{1}$, whereas the $S$ wave of the intraventricular lead corresponded in time to the late $R^{\prime}$ of the precordial tracing. In one case the precordial $R$ wave was distinctly bifid and the late $R^{\prime}$ had a notch on its descending limb (Fig. 8). This notch corresponded in time to the nadir of the $S$ wave of the intraventricular lead, and this part of $R^{\prime}$ is clearly attributable to the activation of the 
free wall of the right ventricle. The depression which separates the $R$ and $R^{\prime}$ deflections in Lead $V_{1}$ corresponds in time to the notch on the intraventricular $R$ wave and it seems likely that both represent the effect of forces produced by activation of the free wall of the left ventricle. Thus, in those cases of complete right bundle branch block in which the secondary $R^{\prime}$ wave in Lead $V_{1}$ is broad, and particularly when it is notched, the first part of this deflection is evidently due mainly to activation of the septum from left to right, whereas its final part represents activation of the free wall of the right ventricle. In cases of right bundle branch block in which the $R^{\prime}$ deflection of Lead $V_{1}$ is slender and unnotched, it is still uncertain whether it is due solely to activation of the free wall of the right ventricle, or contains septal components also.
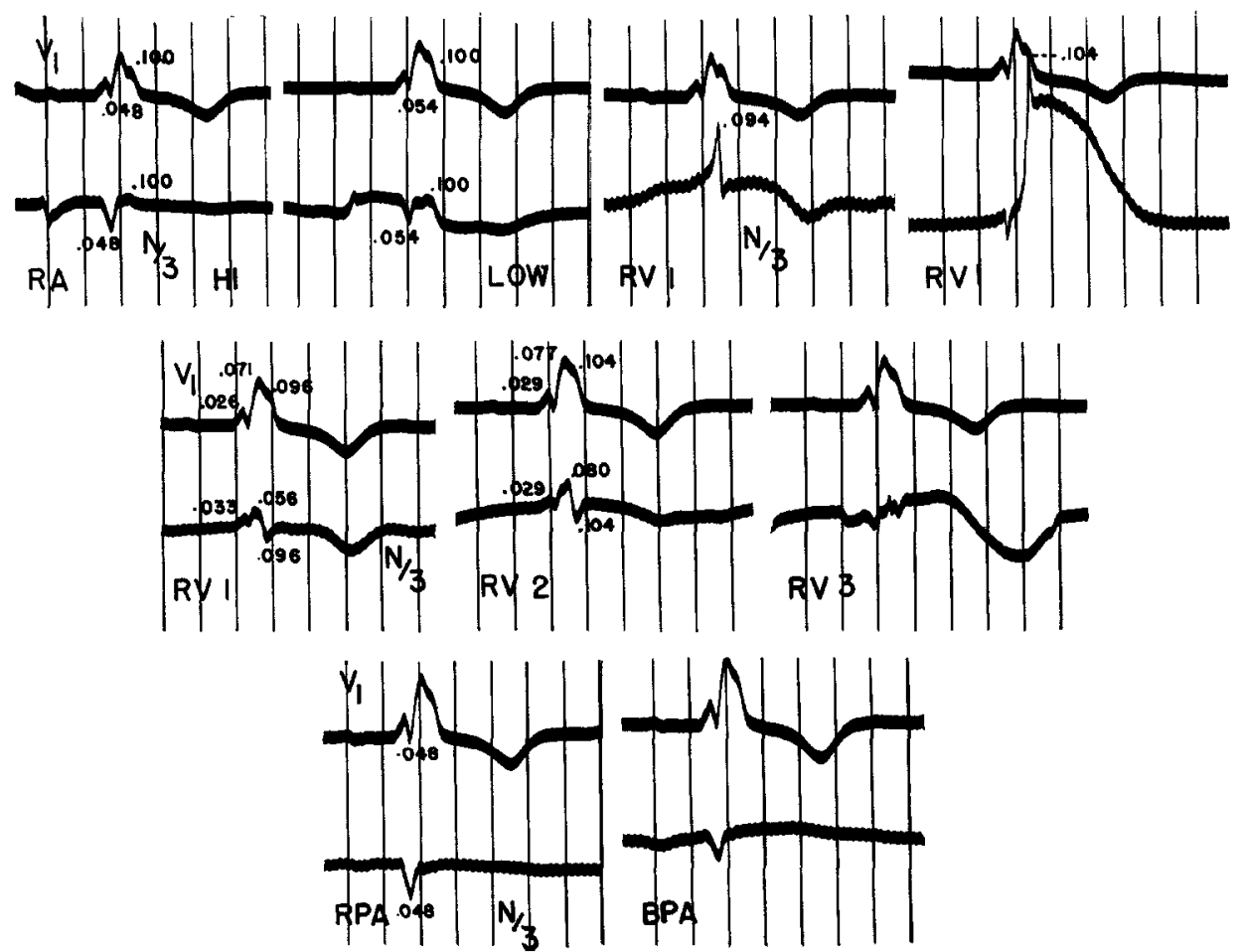

Fig. 8.-Right bundle branch block. Upper beam, Lead $V_{1}$. Upper row, the first two strips show leads from the right auricle. The last two strips show a lead from Position $I$ in the right ventricle, with the catheter tip first about $1.0 \mathrm{~cm}$. from the endocardium and then in contact with it. The second row shows leads from three positions in, the right ventricle. The tracing from Position III shows numerous artifacts. The two strips of the third row show leads from the right pulmonary artery $(R P A)$ and the bifurcation of the pulmonary artery $(B P A)$. The small numbers record in seconds the time of the adjacent peaks in relation to the beginning of the QRS complex in Lead $V_{1}$ or in the cavity lead.

One of our records shows a QRS complex of the normal type, indicating that the bundle branch block temporarily disappeared. In Lead $V_{1}$ this complex is of RS form and measures 0.08 second in duration. In the lead from the right ventricle the same beat is represented by a QS complex or a downward deflection preceded by a tiny $R$ wave. The intracavitary $R$ wave measured 0.04 
second in duration in one and 0.09 second in the other case of right bundle branch block. In our other cases the duration of this deflection averaged about 0.02 second, the minimum being 0.010 second and the maximum, 0.035 second (the latter occurring in the tracing of a normal subject). The height of this $R$ wave deflection in the two cases of right bundle branch block was no greater than its height in our other cases, and it seems unlikely that its voltage can be depended upon to differentiate between right bundle branch block and normal intraventricular conduction. On the other hand, its duration may be helpful in making this differentiation.

In our two cases of right bundle branch block the intra-auricular leads displayed a broad, late $R$ wave similar to that present in Lead $V_{R}$.

Group 3. Left Ventricular Enlargement.-There were three patients in this group, all with prominent left ventricular enlargement. In all of them the leads from the right ventricle displayed a small initial $\mathrm{R}$ wave (Figs. 5 and $9 B$ ). The duration of this deflection was approximately the same as in the cases of right ventricular enlargement, but on the whole its amplitude was smaller. If its small size were due to less early activation of the left side of the septum, one would expect the $Q$ waves of the leads from the left side of the precordium to be correspondingly reduced in size. In the few patients whom we were able to examine, this was not the case. There are cases of left ventricular enlargement in which the initial $\mathrm{R}$ wave of the leads from the right side of the precordium is minute or entirely absent and intracavitary leads would be of great interest in such cases. No cases of this kind are included in our series.

In two cases there was a late $\mathrm{R}$ wave in the leads from the lower portion of the right auricle (Fig. 9B). It is suggested that this deflection was due to activation of the base of the left ventricle. In one of these Lead $V_{R}$ displayed a similar deflection (Fig. 9A). In the remaining two cases the QRS complex of Lead $V_{R}$ consisted of a QS complex.

The $T$ waves were inverted in the intraventricular leads in one case and low but upright in the other two. The $\mathrm{T}$ waves were upright in the leads from the right side of the precordium but inverted in all those from the left side in all three cases.

Group 4.-The remaining four patients form a heterogeneous group, but in none was cardiac enlargement present. The intracavitary $R$ waves corresponded closely in time with the $R$ waves of Lead $V_{1}$. In all instances but one the initial $R$ wave of the right ventricular cavity measured less than 0.024 second in duration and was not conspicuously tall. The exceptional patient was a young man of twenty without apparent heart disease whose tracings in the leads from the right ventricle displayed $R$ waves which were unusually broad $(0.035$ second) and tall compared with the $\mathrm{S}$ wave (Fig. 10B). This patient's precordial electrocardiogram showed a QRS interval of 0.09 second, tall $\mathrm{R}$ waves in the leads from the right side of the precordium, especially Lead $V_{E}$, and $Q$ waves in Leads $V_{5}$ and $V_{6}$ (Fig. 10A). In Lead $V^{\prime}{ }_{4}$ (a lead from the right side of the chest corresponding to Lead $\mathrm{V}_{4}$ ) the sole QRS deflection was upward. We have 


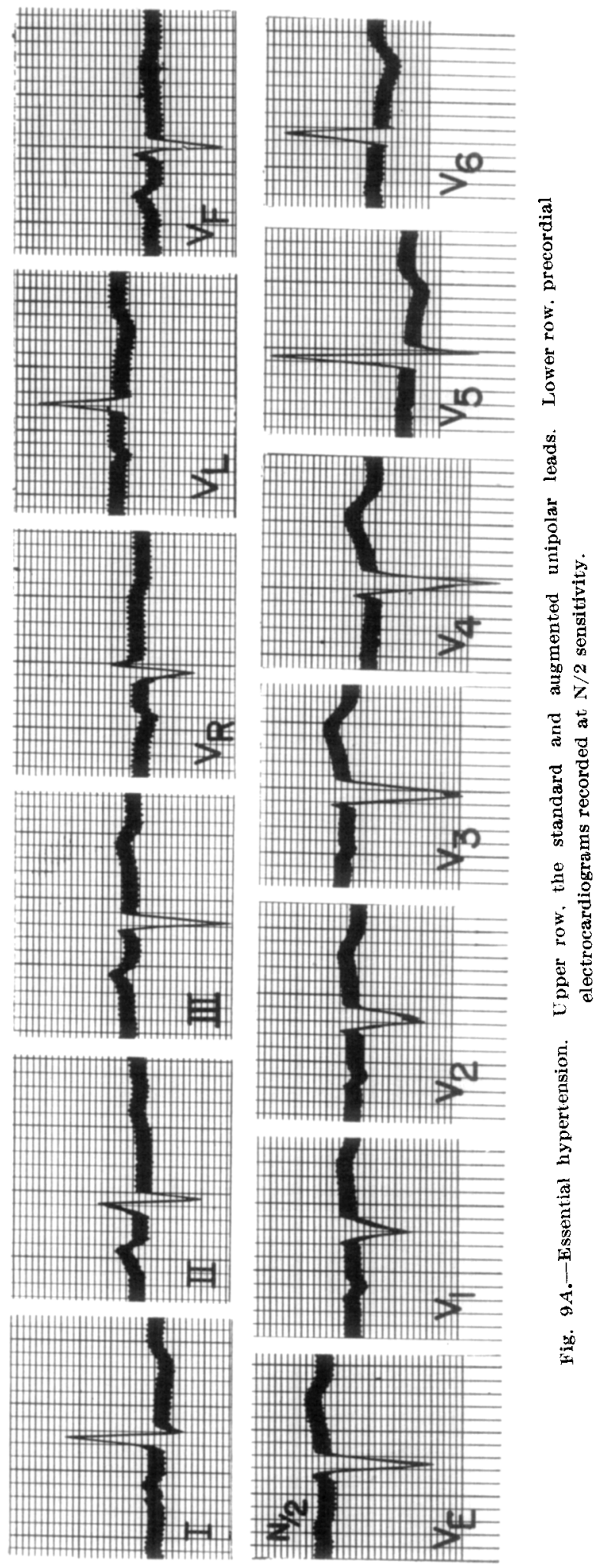


wondered whether an abnormal delay in the activation of the right ventricle was present in this case. Certainly, if intracavitary leads and leads from the right side of the chest had not been taken, no abnormality would have been suspected. It is our opinion that in some normal subjects the normal difference in the time of activation of the two ventricles is greater than it is in others.

\section{SUMMARY AND CONCLUSIONS}

Intracavitary electrocardiography is useful for the purpose of ascertaining the effects of activation of the free wall of the right ventricle upon the form of the QRS complex of Lead $V_{1}$ in cases of right ventricular enlargement and right bundle branch block. The order in which the inner and outer layers of this wall are repolarized is disclosed by this method only when the $T$ waves of the leads from the ventricular cavity and those of the leads from the right side of the precordium are opposite in direction.

1. In right ventricular enlargement the large $R$ wave in Lead $V_{1}$ represents the activation of the free wall of the right ventricle. Notches or slurs on the upstroke of this deflection are apparently due to the activation of the septum

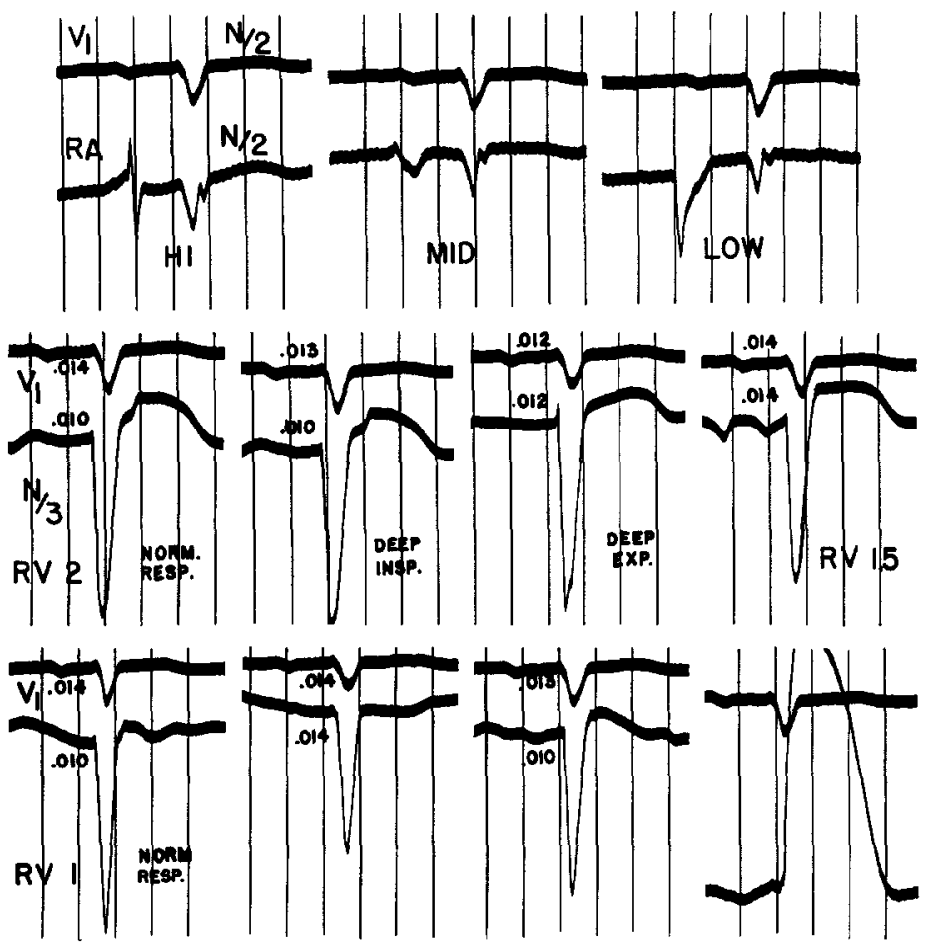

Fig. 9B.-Same patient as Fig. 9A. Upper beam, Lead $V_{1}$. First row, leads from the right auricle. Second row, the first three tracings show a lead from Position II in the right ventricle during normal respiration, deep inspiration, and expiration, respectively. Last tracing of the second row is from position in the right ventricle midway between Positions I and II. Lower row, leads from Position $I$ in the right ventricle during normal respiration, deep inspiration, and expiration, respectively. Last tracing taken when catheter tip was against endocardium at Position $I$. 

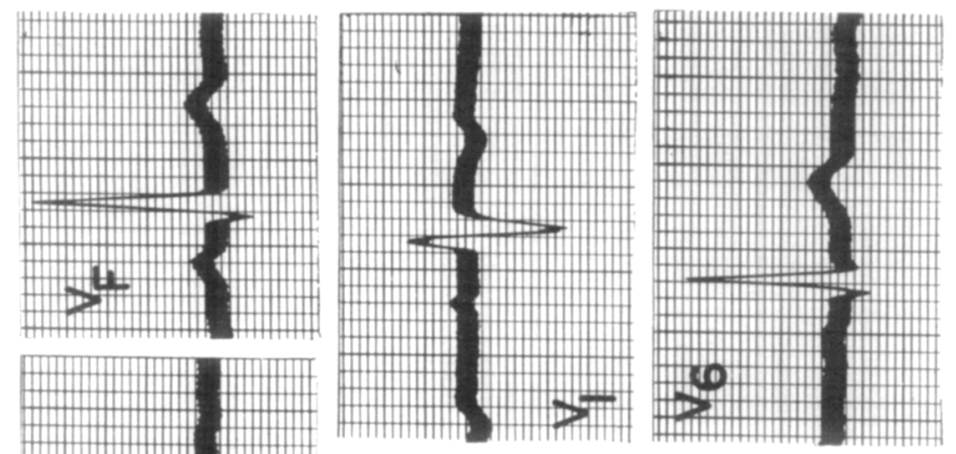

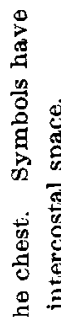
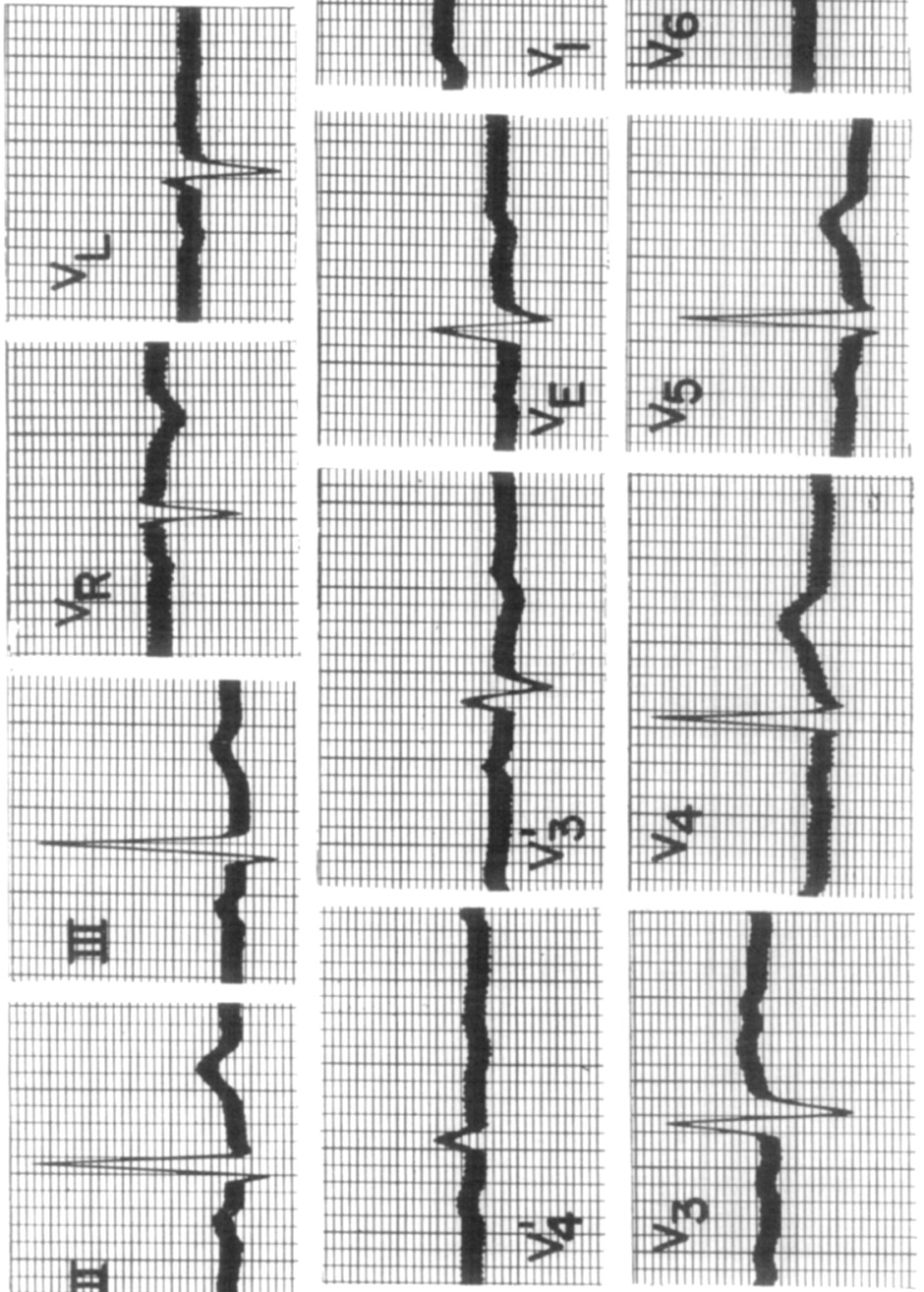

ज्ञ

댕

邑

交员

몸

ㄷํำ

骂

$\Phi$

를

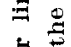

峞

音

ए

है

要

क

혼

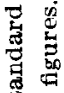
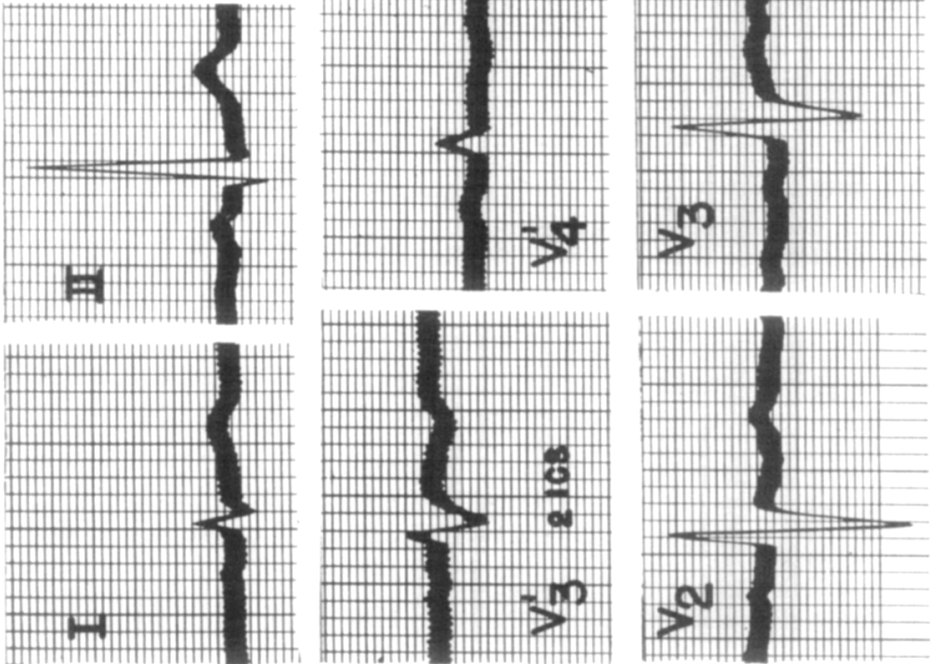

需

.

㻤

古

芯

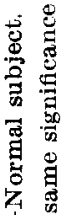

용

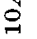

$\stackrel{0}{10}$

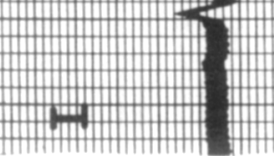


from left to right and do not justify the conclusion that the right ventricle is activated abnormally late. In some cases of right ventricular enlargement in which there is a $Q$ deflection in Lead $V_{1}$, there is a simultaneous $Q$ deflection in leads from the cavity of the right ventricle. The origin of this $Q$ wave is obscure.
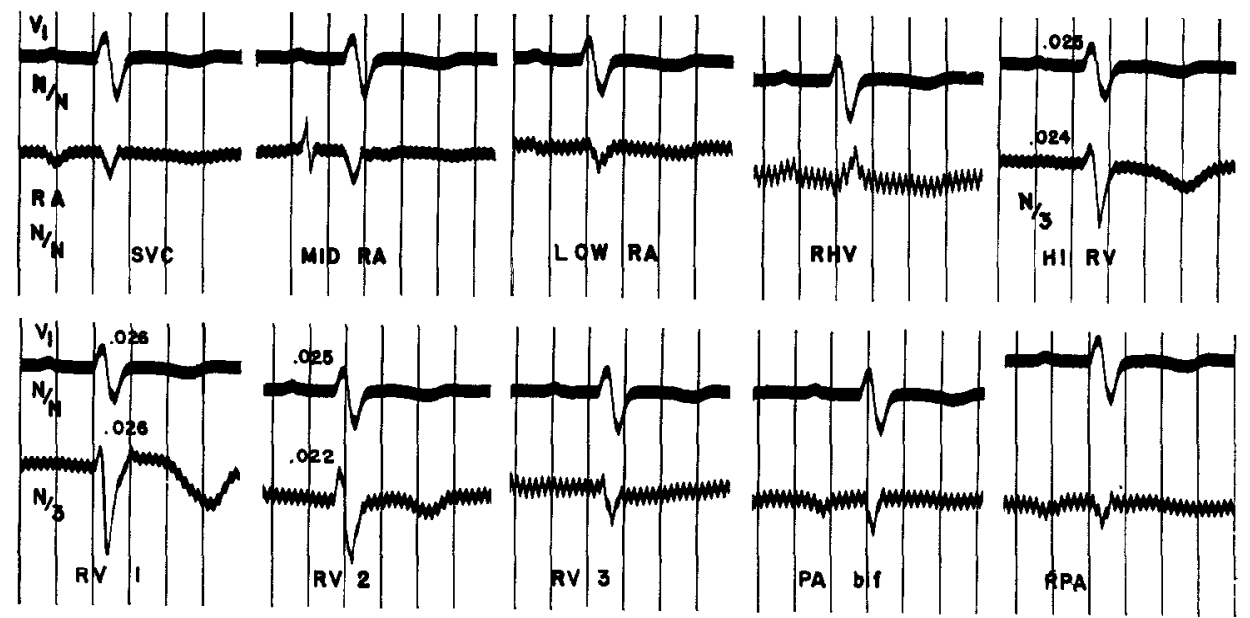

Fig. 10B.-From the same patient as Fig. 10A. Upper beam, Lead $v_{1}$. Lower beam, leads from superior vena cava $(S V C)$, mid-position in the right auricle (mid $R A$ ), lower position in the right auricle (low $R A$ ), and right hepatic vein $(R H V)$. Hi $R V$ is the same as Position I in the right ventricle $\left(R V_{1}\right)$, but the latter is from a point closer to the endocardium. $R V_{2}$ and $R V_{3}$ equal Positions II and III in the right ventricle. Last two strips show leads from the bifurcation of the pulmonary artery (PA bif) and from the right main branch of the pulmonary artery. Unfortunately, 60 cycle current was superimposed on several of the tracings.

2. In right bundle branch block the initial $R$ wave in Lead $V_{1}$ is due to the activation of the septum from left to right. In those electrocardiograms in which the secondary $R$ wave in Lead $V_{1}$ is broad and notched, the initial portion of this secondary $R$ wave is due to the activation of the septum, and its final portion, to activation of the free wall of the right ventricle.

The height of the intracavitary $R$ wave is not a useful criterion for the purpose of diagnosing conduction defects in the right branch of the bundle of His, but its duration may prove to be of greater value.

3. In normal subjects and in patients with left ventricular enlargement, the early activation of the septum from left to right contributes to the $R$ wave of Lead $V_{1}$ and is responsible for the $Q$ wave that occurs in Leads $V_{5}$ and $V_{6}$.

4. Leads from the cavity of the right auricle and Lead $V_{R}$ usually reflect the late activation of the base of the right ventricle when it is hypertrophied, and may in other instances reflect the late activation of the base of an hypertrophied left ventricle.

5. In some normal individuals the difference in the time of activation of the two ventricles is greater than in others. This greatly complicates the diagnosis of incomplete right bundle branch block. 
6. In the free wall of the right ventricle the repolarization process ordinarily advances from the epicardial toward the endocardial surface.

The authors are greatly indebted to Dr. Frank N. Wilson for his many valuable suggestions and for his help in the preparation of this paper.

\section{REFERENCES}

1. Wilson, F. N., Johnston, F. D., and Hill, I. G. W.: The Interpretation of the Galvanometric Curves Obtained When One Electrode is Distant From the Heart and the Other Near or in Contact With the Ventricular Surface, Am. He ART J. 10:196, 1934.

2. Wilson, F. N., Johnston, F. D., Rosenbaum, F. F., Erlanger, H., Kossmann, C. E., Hecht, H., Cotrim, N., Menezes de Oliviera, R., Scarsi, R., and Barker, P. S.: The Precordial Electrocardiogram, AM. HEART J. $27: 19,1944$.

3. Forssmann, W. I.: Die Sondierung des rechten Herzens, Klin. Wchnschr. 8:2085, 1929.

4. Hecht, H.: Potential Variations of the Right Auricular and Ventricular Cavities in Man, Am. Heart J. 32:39, 1946.

5. Battro, A., and Bidoggia, H.: Endocardiac Elcetrocardiogram Obtained by Heart Catheterization in the Man, AM. HearT J. 33:604, 1947.

6. Sodi-Pallares, D., Vizcaino, M., Soberon, J., and Cabrera, E.: Comparative Study of the Intracavity Potential in Man and in Dog, AM. HearT J. 33:819, 1947.

7. Marcu, I.: Experimental Extrasystoles Elicited Through Artificial Stimulation of the Endocardium of the Dog, AM. HEART J. 12:301, 1936.

8. Wilson, F. N., Macleod, A. G., and Barker, P. S.: The Distribution of the Action Currents Produced by Heart Muscle and Other Excitable Tissues Immersed in Extensive Conducting Media, J. Gen. Physiol. 16:423, 1933. 